\title{
Potential for Applying Open Innovations in Tourism
}

\author{
Assoc. Prof. PhD Velina Kazandzhieva \\ University of Economics - Varna, Varna, Bulgaria \\ velina_kaz@ue-varna.bg
}

\begin{abstract}
For more than a decade the so-called "open innovations" attract the attention of academic circles and business. In the modern competitive and dynamically developing tourism it is of paramount importance for companies to be innovative and use diversely the potential for updating their products and services. The goal of this article is on the ground of a theoretical characterization of open innovations to determine their particularities and present variants for applying them in the sector of tourism. The paradigm of open innovations in tourism is based on the understanding that innovative processes are put in practice not only in the framework of tourist companies, but they also integrate a number of subjects from the outside in order to increase the potential of innovations and changes. The success of open innovations depends on the abilities of tourist companies to create effective networks with other stakeholders: suppliers, partners, clients, institutions, non-governmental organizations and others.
\end{abstract}

Keywords: open innovation, tourism services, crowdsourcing in tourism, destination.

JEL Code: Z300; doi:10.36997/IJUSV-ESS/2019.8.3.28

\section{Introduction}

The development of modern tourism is characterized by exceptional dynamics and intensity. The tourist industry faces considerable challenges in respect to the influence of factors such as fragmentation and complexity of the sector; global competition and rapidly changing structures, processes and products; changes in the needs, values and standards of clients and many others. The dynamics of the tourist market is additionally accelerated by the application of information and communication technologies that are a powerful factor responsible for establishing a new balance between consumers, intermediaries and suppliers in the system of tourism. Clients' expectations increase together with the chance for them to have a proactive role in the value generation chain. The systematized circumstances require from tourist companies to adopt a modern innovative approach. The sector of services, including those in tourism, falls behind in respect to innovations. Discussions in scientific literature about innovative approaches in tourism are not common, even though in the fields of tourism business there are examples for openness and collaboration.

Actually, it is not easy to determine innovations in servicing because in most cases they are created through the active cooperative participation of clients. Innovations in the service sector differ from those in production and high-tech industries simply because the services and processes, through which they are created, are complex and it is difficult to divide them in comparison to products (Djellal \& Gallouj, 2010; Hogan et al., 2011; Love et al., 2011). The use of external sources of knowledge by consumers and suppliers is of significant importance for the success of innovations, especially for those in the field of tourism. Internal openness is also a decisive factor for success. The team approach in the process of tourist services is an important concept that integrates simultaneous accumulation of knowledge and information exchange, increases the innovation efficiency and trust and strengthens the functional inter-team interactions.

Open service innovation is a comparatively unexplored area of research (Mina et al., 2014). The current publication is a qualitative study on an open innovation processes used in tourism services. They are characterized by high degrees of intangibility, inseparability, perishability and heterogeneity, because tourism firms often add experiential components to their core offerings in the form of "comprehensive living adventures" (Stamboulis \& Skayannis, 2003, p. 38).

The subject of research in the article is open innovation and the object of survey is the potential for putting into practice the processes of open innovations in tourism. The goal set in the publication is: on the ground of a theoretical characteristic of the nature of the open innovation 
approach to determine its specifics of application in updating and improving tourist services. There are systematized examples for successfully implemented projects for open innovations in various subsectors of tourism. The definition and characteristic features of open innovation have been studied in a theoretical aspect on the ground of a critical review, analysis and synthesis of relevant publications on the topic in the last two decades. By the use of a process-oriented approach there are presented variants of open innovation. Besides, on the ground of a comparative characteristic there are defined the more significant differences between the closed and the open innovation model.

\section{Essence, definition and research perspectives of open innovation}

The insecure business environment and the increased competitiveness require the application of new approaches for companies' adjustment including adaptation of tourist changes to dynamic ones. Similar approaches include interactions with clients (travellers and tourists), suppliers, consumers, research organizations and competitors. These processes are stimulated by the open innovations that express companies' abilities to overcome their own limitations and adopt knowledge and technologies from their surrounding environment (Chesbrough, 2006). Thus they simply proceed from a closed, classical innovation process, in which a product is created in a scientific research company department or is ordered by an external contractor, to a flexible open model which uses out-of-company ideas, products and services. The latter combine with each other, in-company ones are added, thus, on this ground innovation approaches are created to serve the company goals. In this way risk is lower due to a combination of external possibilities and internal innovation resources.

The author of the concept of open innovation is Henry Chesbrough, who defines it as: „, the use of purposive inflows and outflows of knowledge to accelerate internal innovation, and expand the markets for external use of innovation, respectively" (Chesbrough, 2006, p. 1). Later this definition was added, enlarged and presented as follows: ,, a distributed innovation process based on purposively managed knowledge flows across organizational boundaries, using pecuniary and non-pecuniary mechanisms in line with the organization's business model (Chesbrough \& Bogers, 2017, p. 4). According to Chesbrough, the paradigm of open innovation is an antithesis of the vertical-integration model. In open innovation internal company abilities are combined with the external ones, unlike vertical integration where by use of in-company research and development activity there are created products for distribution outside the organization framework.

Open innovations are based on the idea of being implemented not only within a specific company; instead, the innovation process involves also the external environment in order to increase its potential. A core reason for applying the concept of open innovation is the on-going change in the dynamics of the environment and the fact that companies are unable to put in practice their internal research and development activity as successfully as they would in using external knowledge. To this reason one adds the increasing competitive pressure, globalization and the shorter lifecycle of products and services. To a considerable degree the success of innovations depends on the ability of a particular company to create and maintain networks with stakeholders like suppliers, clients and other entities. Actually, open innovations are divided into three main processes:

* outside-in process - it refers to integrating external knowledge in the process of innovation. A company should use knowhow from suppliers, clients and external partners (universities, research institutes, consultants and others) in order to increase the quality and speed of the innovation process. An example of a similar process is the involvement of progressive consumers in developing new products and services. The outside-in process shows that the location of creating new knowledge does not coincide with the place where it is implemented.

* inside-out process - this refers to putting internal knowledge into practice through selling (or assigning) to external contractors. Companies use this process to make profits from license fees for patents or innovations that aren't used for their own business operations. The inside-out process 
shows that the location where knowledge and innovations occur usually does not coincide with the place innovations are used for creating new products and services.

* coupled process - a combination of both processes above. External knowledge is integrated in combination with assigning the implementation of internal knowledge to external contractors. The coupled process focusses on creating regulations and market development. The various types of environment play essential role in the development of innovations, at the same time they lead to the emergence of innovation market.

According to Gassmann \& Enkel (2004) these three core processes are key in defining the open innovation paradigm (Figure 1). In closed innovation a company relies completely on its own resources and usually makes large investment in innovation activities. In open innovation the company making innovation doesn't have to own large resources, instead it uses those of its external partners as part of the innovation process (Figure 2). Thus the resources (visible and invisible) are shared and innovations are implemented in cooperation which favors all partners. Open innovations are based on research-and-development activities characterized by Grassmann et al. (2010, pp. 213-214) through the prism of the following research perspectives:

* spatial - derives from the globalization aspects of innovation and the dynamics in the development of information and communication technologies which supports the adoption and application of open innovation;

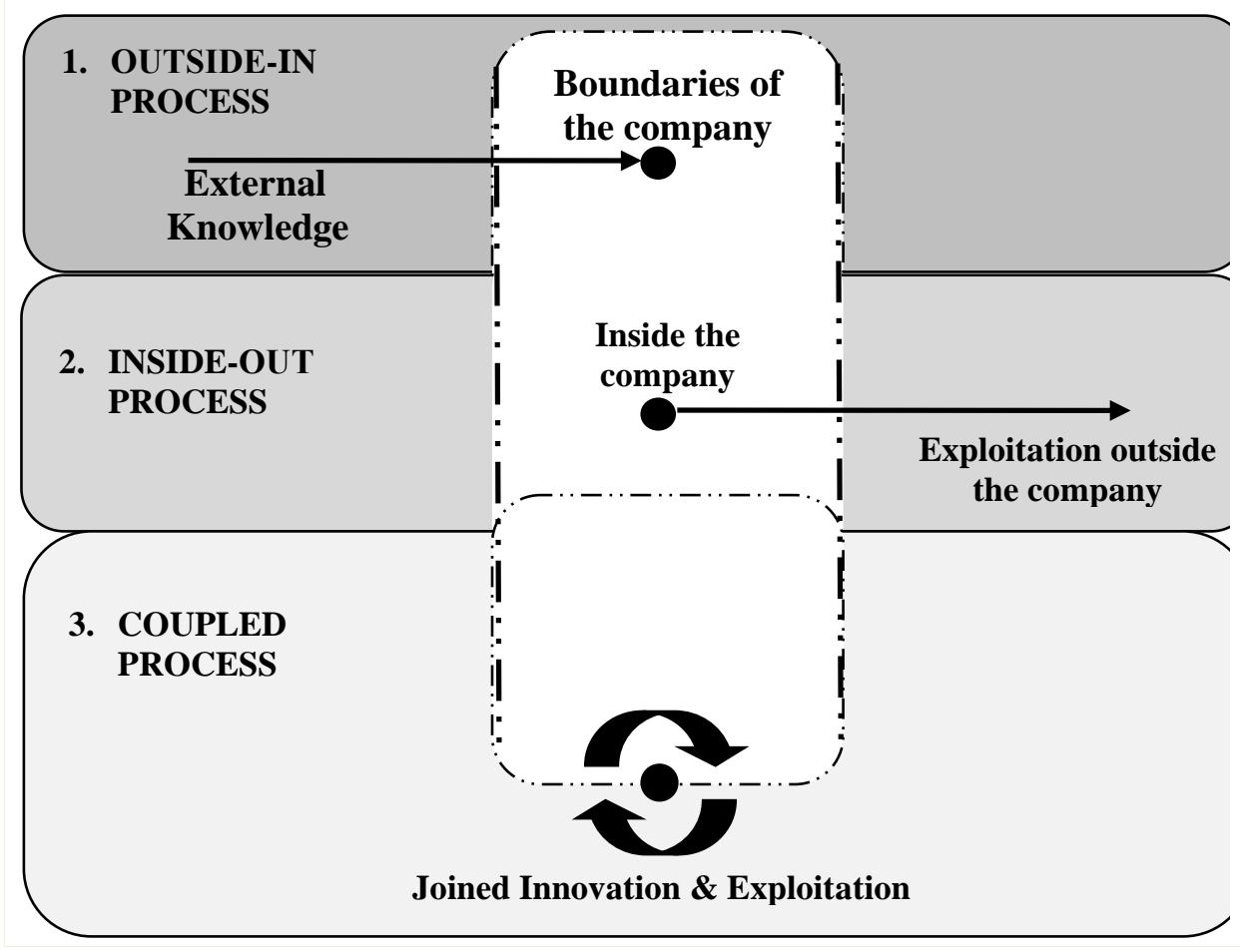

1. Inbound or outside-in
process: integrating of
customers, suppliers and
external knowledge sources to
complement and enrich a
company's existing capabilities.

2. Outbound or inside-out process: externally exploiting ideas in markets, multiplying technology and selling innovation process ideas outside the boundaries of the company.

3. Coupled process: working in alliances with external complementaries and linking outside-in and outside-out.

Figure 1. Open Innovation Processes (Gassmann \& Enkel, 2004, p. 7)

* structural - shows that work division has increased in innovation. Industries' value chains are becoming more disaggregated. Driver of this trend is cost reduction and larger specialization thanks to additional complex and advanced technologies and product/service systems;

* user perspective - emphasis is put on involving users in all stages of the innovation process, in this way companies can be proactive when satisfying consumer needs. User innovation is one of open innovation's best-researched part fields;

* supplier perspective - the integration of suppliers at early stages of the open-innovation process increases competitive presentation considerably; 
* leveraging perspective - emphasis is placed on business models and the opportunities to develop them. Creating technologies and commercialization of external intellectual property have high potential for the future development of companies that apply the concept of open innovation;

* process perspective - there are three core processes in opening up the innovation process: outside-in, inside-out and coupled. Sometimes, these processes complement each other, though the dominance of the outside-in process is generally observed; one another, although the dominance of the outside-in process is usually observed;

* tool perspective - opening up the innovation process requires a set of instruments to enable customers to create or configure their own product/service or enable companies to integrate external problem solvers or idea creators via websites;

* institutional - open innovation can be considered a private-collective innovation model. The free revealing of inventions, findings, discoveries and knowledge is one of the defining feature of the open innovation model. Spillovers of proprietary knowledge occur regularly by means of compensation (e.g., licensing) or without compensation (e.g., most open source initiatives);

* cultural - creating a culture that values outside competence and know-how is crucial for open innovation practice. This culture is influenced by many factors: the values of the company; the artefacts such as incentive systems, management information systems, communication platforms; project decision criteria; provider evaluation lists, its handling and so on. In order to raise perceive the influence of all those aspects on the open innovation culture, analysis ought to draw a lot from the psychological field.
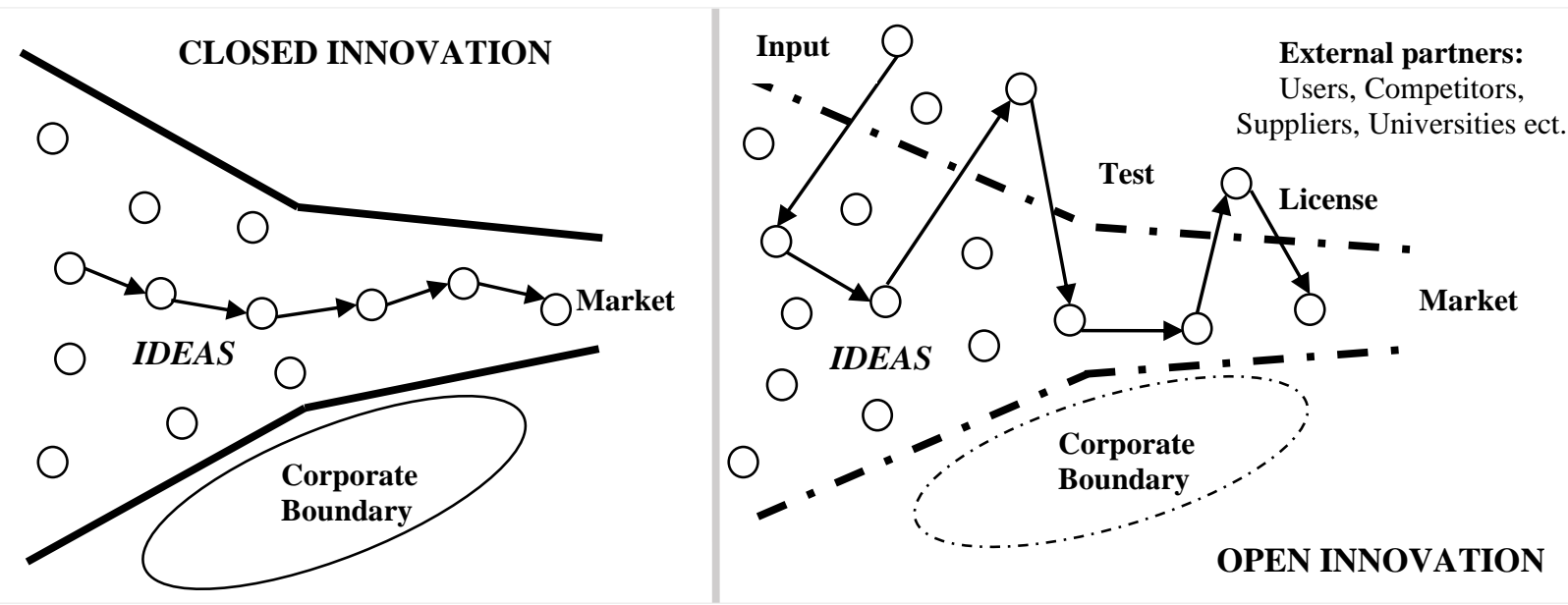

Figure 2. Closed vs. open innovation model (Egger et al., 2016, p. 6)

A basic barrier to adopting the concept of open innovation is that a company is afraid to lose the right of its own patents, production or commercial secrets as a consequence of sharing information and knowledge with other organizations. The negative consequence of open innovations is the creation of business models that are too open and lead to complex and uncontrolled systems.

\section{Features of service innovation in tourism}

Innovation in tourism is the result of patterns that are different from those in manufacturing. One of the main differences is that almost all innovations in services don't seem to be technological, however include a modification of behavior (Sundbo et al., 2007). Tourism innovations are difficult to establish and at the same time relatively easy to imitate, particularly once front stage processes are extremely visible and therefore the level of technology is comparatively unsophisticated (Hjalager, 2002; Sundbo et al., 2007; Paget et al., 2010). Innovation in tourism has some distinct characteristics (Hall \& Williams, 2008, pp. 11-13): 
intangible;

$\checkmark$ tourism services at the same time involve production and consumption and are largely

$\checkmark$ the total tourism experience is created of and outlined by multiple encounters with tourism providers;

$\checkmark$ the tourism industry is heavily dependent on information exchanges, whether in terms of information provided to tourists or the data accumulated by tourism companies about travellers;

$\checkmark$ most tourism sub-sectors are labor-intensive and therefore the quality of the labor input shapes the tourism experience;

$\checkmark$ organizational factors are of great importance in tourism. The multiple encounters with completely different service suppliers that represent a major a part of the tourism experience is also coordinated via a web of economic, communicative and social networks of producers.

Research has shown that service firms rarely carry out traditional Research \& Development (R\&D) internally, although the implementation of R\&D-embodied technology is often a source of innovation in services, and in tourism services in particular (Orfila-Sintes et al., 2005). In a broad sense, innovation in the tourism sector is defined as "the generation, acceptance and implementation of new ideas, processes, products or services” (Hall \& Williams, 2008, p. 5). The distinction among process, product, and service innovation in service industries is difficult because "new services often go together with new patterns of distribution, client interaction, quality control and assurance, etc." (Jong et al., 2003, p. 17).

The specific characteristics of tourism services (intangibility, inseparability, perishability, heterogeneity) affect the types of open innovation practice that are relevant when new tourism services and products are developed. The inseparable nature of these services imply that inbound open innovation practices in which knowledge from customers is used to accelerate innovation may be highly relevant for tourism firms (Carbonell et al., 2012; Hall \& Williams, 2008; Buhalis, 2000;). This proposition is supported by empirical research. In a study of experience-based tourism Stamboulis and Skayannis (2003) found that first movers among the customers are an important source of knowledge during the innovation processes.

The knowledge of external actors indirectly involved in the co-creation of services is simply too restricted to contribute throughout innovation processes in tourism. Research has confirmed that tourism firms seldom use knowledge from universities and research laboratories during their innovation processes (Hjalager, 2010). In the recent times tourism companies have enforced abundant new technology each to streamline the inner processes and to enhance the services provided. The knowledge is embedded in this technology, implying that the implementation of new technology indirectly involves the transfer of knowledge from technology suppliers to tourism firms (Evangelista, 2000). An important characteristic of successful outbound open innovation is that it is possible to separate systems in specific modules of knowledge that can be sold or shared to other actors during innovation processes. The intangible and perishable nature of tourism services could complicate modularization of tourism services and this could cut back the relevance of outbound open innovation in tourism (Aas \& Pedersen, 2016). Purposive inflows of knowledge from customers within the early stages of the innovation process usually had a non-pecuniary nature. External actors are also involved during the early stages of the development of more radical innovations, but this involvement is typically more indirect.

\section{Applying open innovations in tourism}

Contemporary tourism markets are highly saturated, with falling profit margins, fast changing needs and customer demands. The tourism industry is organized in a traditional way and products and services are becoming more and more similar and exchangeable. Most of tourism companies are family owned and managed SMEs and authenticity, uniqueness, tradition and adhering to standard principles are appreciated by most tourists. At the same time, the risk of missing a timely adaption to advanced technological and societal transformations can be also 
observed. The open innovation approach has the potential to guarantee the survival of tourism companies in this turbulent environment. In the tourism, the opening of corporate boundaries to accommodate external input comprises innovation processes and main functions, such as marketing, communication and the execution of travel and tourism services. The main transformations and challenges for the tourism industry triggered by hi-tech advances and social media platforms (Facebook, Tripadvisor and Youtube) can be summarized as (Egger et al., 2016, p. 5): opening of operational boundaries (principle view); opening of economic boundaries (cost view); opening of institutional boundaries (ability view); opening of behavioural boundaries (motivation view). In compliance with the above-stated changes and for the goals of this study open innovation in tourism needs to be accepted as: a complex and integrated process of opening the tourist companies' corporate boundaries for flexible and efficient use of entry, exit and combined new knowledge from and to external partners: consumers, suppliers, intermediaries, competitors, consultants and others.

As already mentioned, the sphere of services lags behind in in adopting open innovations. The review of specialized literature shows that there exists a delay in using open innovative approaches in tourism, mostly due to the specifics of tourist services. At the same time the chances for openness and cooperation in the tourist industry are not few at all. The transformations in the traditional business models of distributing tourist services result into the emergence of open tourism. The new opportunities stimulate the opening of tourist companies' traditional structures such as, for example, integration of external sources in corporate processes and providing tourist services between individuals in P2P (peer-to-peer) networks. On the one hand, the development of the above-mentioned transformations enriches the tourist industry, yet, on the other, it endangers the traditional participants in the tourist system by creating specific difficulties and challenges for them.

As active participants in the process of creating tourist services, undoubtedly travellers and tourists are among the most significant sources of open innovations through spreading information, opinion and judgement. Guests' contribution for accumulating new knowledge applicable in open innovation goes through the following modifications: describing and informing; creating and providing; assessing and commenting on tourist services (Tripadvisor). A client's personal participation deepens, whereas his/her information contribution, published online for free (in forums and communities of interest) is being analyzed by tourist companies. Experience shared in this way is actually co-creation and co-learning, in this sense the user-generated content is a favourable opportunity for generating ideas for open innovations. The influence caused by the online word of mouth is especially strong in the travel and tourism industry and it will continue to strengthen, because online reviews have a dual role: they provide information about products and services and, at the same time, work as proposals and useful suggestions for innovations.

Even more companies use crowdsourcing by involving clients in making new products and services. Thus, through gathering information from collective reasoning or from the public (the literal meaning of "crowdsourcing") companies save costs and accumulate new ideas for open innovation. Firms use the new platform by assigning various tasks to a large group of people from the outside, most often online users. These can be clients of the respective companies and could get a small payment. The involvement of users increases their trust in the product or service, at the same time it lowers companies' costs. One of the channels of involving users in the new process is social networks. Cloud technologies also contribute for the development of crowdsourcing. An example for its application in the travel and tourism industry is online checking offered to their clients by airline companies. New service ideas, related to the improvement of existing services, are often born outside the borders of the firms. They typically came from existing customers and are often identified by front-line employees, or through surveys or other digital social media channels. Examples of innovations that emerged from customer input/ideas are the establishment of a new dining concept, the upgrading of accommodation or transport facilities, the improvement of tourism territories. Other examples, related to open innovation, crowdsourcing, co-creation and collaborative consumption in tourism are presented in table 1. 
Table 1. Open tourism examples and cases

\begin{tabular}{|c|c|}
\hline \multicolumn{2}{|c|}{ INFORM } \\
\hline TALK - BE ANALYSED & EVALUATE-RECOMMEND \\
\hline $\begin{array}{l}\text { "Smile Land" - part of a digital marketing strategy } \\
\text { initiated by the Tourism Authority of Thailand. }\end{array}$ & $\begin{array}{l}\text { ZAGAT (an information database, helping users to find various } \\
\text { restaurants. Shows detailed ratings given to the restaurants, } \\
\text { reviews and lists, based on feedback from every day customers); } \\
\text { TripAdvisor; Tripwolf (online travel guide); } \\
\text { Qype (Europe's leading consumer review site). }\end{array}$ \\
\hline \multicolumn{2}{|c|}{ CREATE } \\
\hline GENERATE - PUBLISH & CREATE - PROTOTYPE \\
\hline $\begin{array}{l}\text { WizardIstanbul (online travel guide); } \\
\text { "Share Your Washington"; } \\
\text { "35 Million Directors" (a crowdsourcing initiative of } \\
\text { the Canadian Tourism Commission to encourage } \\
\text { Canadians to participate in a new video to promote } \\
\text { Canada as a destination in international markets); } \\
\text { "There Is Nothing Like Australia" (a project of } \\
\text { Tourism Australia to inform travellers more about the } \\
\text { country); "Curators of Sweden" (a project by the } \\
\text { National Board for the promotion of Sweden, } \\
\text { VisitSweden); "Valleys Essentials" (chosen by the } \\
\text { visitors and users of The Valleys' website, Wales); } \\
\text { "It's More Fun in the Philippines"; } \\
\text { "DiscoverIreland"; Louisiana calls all "Festival } \\
\text { fanatics"; My Cape Town holiday; Sauna from } \\
\text { Finland; Flinkster (a car sharing system initiated by } \\
\text { Deutsche Bahn); INNOTOUR (an interactive web } \\
\text { platform that should foster the exchange of ideas and } \\
\text { provide resources to innovation in tourism, Centre for } \\
\text { Tourism, Innovation and Culture of the University of } \\
\text { Southern Denmark). }\end{array}$ & $\begin{array}{l}\text { KLM Must See Map (a website that displays a customisable } \\
\text { map of a chosen KLM destination); } \\
\text { My Indonesian moment (to solicit funny and inspiring stories } \\
\text { from travellers, in the form of writing or photographs); } \\
\text { "Your Big Break" (the New Zealand Tourism Board invited } \\
\text { young filmmakers to contribute a script for a 3-min short film } \\
\text { presenting the spirit of New Zealand); } \\
\text { "Brighter, Bolder, Better" (a global online competition, } \\
\text { launched by Amadeus Corporation, designed to "find innovative } \\
\text { ideas that would help transform the travel experience"); } \\
\text { "99 ideas Call for Pompeii" (to solicit ideas for developing the } \\
\text { attractions); } \\
\text { "InnoWellen" ideas competition (a project to enable and } \\
\text { encourage stakeholders to collectively gather and select new } \\
\text { ideas for the reconstruction of the public swimming pool in } \\
\text { Oberammergau, Bavaria); } \\
\text { "\#Wien2020" ideas competitions (to invite people to submit } \\
\text { their ideas and input for Vienna's new tourism strategy, called } \\
\text { "Wien } 2020 ") ; \\
\text { Aloft Hotels of Starwood (a project to gain feedback from } \\
\text { customers on designs for rooms, restaurants, bars and the hotel). }\end{array}$ \\
\hline \multicolumn{2}{|c|}{ PROVIDE } \\
\hline FUND-INVEST & SHARE - PRODUCE \\
\hline $\begin{array}{l}\text { "Up Greek Tourism"(a crowdfunding to finance } \\
\text { tourism promotion campaigns in London, Washington } \\
\text { DC, NY); } \\
\text { Cleaning Up the Yellow-Stone National Park (use of } \\
\text { crowdfunding to generate the resources necessary); } \\
\text { Investours - Mexico (to provide funds for small } \\
\text { tourism businesses in developing countries, based on } \\
\text { creating human networks and exchanging knowledge). }\end{array}$ & $\begin{array}{l}\text { \#LoveCapeTown Campaign (a campaign by the Cape Town } \\
\text { tourism office, part of an award-winning e-marketing strategy } \\
\text { focusing on using citizens and fans as ambassadors for the } \\
\text { destination); Airbnb (a platform where people from all over the } \\
\text { world can market their extra space and thus offer others the } \\
\text { possibility of having a unique travel experience); } \\
\text { Couchsurfing (a global community creating unique travel } \\
\text { Experiences); "Visit a Swede" (an initiative of the National } \\
\text { Board to provide a unique travel experience for travellers by } \\
\text { meeting with locals, VisitSweden); } \\
\text { Travel2change (an online community of travellers and locals, } \\
\text { with the aim to create a change - "travel changes lives"). }\end{array}$ \\
\hline
\end{tabular}

Source: Examples are selected from Allerstorfer et al., 2016, pp. 447-469.

Crowdsourcing is the logical sequence of outsourcing, however, these two tools differ. In crowdsourcing tasks are delegated not only to professionals but amateurs as well (travellers, tourists, guests) and one relies on external collective knowledge. The process is cheaper and faster, it is used for generating ideas. Tourist companies can search for collaboration from clients by encouraging them to share interesting ideas for a slogan, logo, new product or tourist service. Attracting informed and active users is a winning strategy for tourist companies and has the potential to displace outsourcing. 
The open innovation approach is suitable for improving the management of the innovation approach in destinations. Research on the topic in the Alpine tourist industry in the region of Tirol, Austria, shows that in this case open innovation is usually driven by cooperation and entrepreneurship (Pikkemaat \& Peters, 2016). Cooperation should be facilitated by government as well as knowledge (project and innovation management ideas) and know-how initiatives (platforms, workshops, expert excursions, etc.). Employees and guests have a smaller contribution to managing open innovation. Destination management organizations can provide support for active search, prior knowledge and networking, but also for the awareness of its destination stakeholders to recognize potentially valuable opportunities. The destination is a amalgam of very different companies with different research and development imperatives. In a regular tourism market, once the firms accept the notions of interorganizational innovation collaboration, every entrepreneur "who does not participate will cope with serious competitive disadvantages" (Enkel et al., 2009). Destination governance structures could focus on a greater inclusion of small business sub-networks or associations. Open innovation demands flexible destination networks which allow the development of innovations based on the destinations core resources and external stimuli. The latter can be created by an increase in market research activities including market trends dissemination amongst destination stakeholders. It might be an advantage to consider the inclusion of destination external stakeholders (international experts from different industries) in the tourism boards within the destination.

\section{Conclusion}

This study has shown that open innovations are suitable for applying in the tourist industry on all levels: international, national, regional, local and company. Despite the lagging behind from the field of production, open innovation processes can be adapted to the specifics of tourist services and implemented in the various tourist subsectors through different projects. The effectiveness of such projects is based on the active use of crowdsourcing and the large involvement of consumers in joint initiatives for creating, sharing and promoting tourist services, experiences and tourist experience. In destinations the basic drivers for open innovations are the various forms of cooperation, collaboration and entrepreneurship initiated by the organizations for managing destinations or other local managerial structures. The key factor for success of each open innovation in tourism is the active interaction between organizational/company subjects and their external partners. In this way accumulation, exchange and distribution of new knowledge can generate sustainability of tourist companies in respect to the challenges and difficulties of the dynamic business environment.

\section{References}

1. Aas, T.H., \& Pedersen, P.E. (2016). 'The feasibility of open service innovation', in A.L. Mention and M. Torkkeli (eds.) Open Innovation: A Multifaceted Perspective. Vol. 1. England, London: World Scientific Publishing, pp. 287-314.

2. Allerstorfer, P., Boes, K., Gula, I., Horvath, Z., \& Ronay, E. (2016). 'Further Open Tourism Examples and Cases', in Egger, R., Gula, I., Walcher, D. (eds.) Open Tourism: Open Innovation, Crowdsourcing and Co-Creation Challenging the Tourism Industry, SpringerVerlag Berlin Heidelberg, pp. 447-469.

3. Buhalis, D. (2000). 'The tourism phenomenon: the new tourist and consumer', in C. Wahab, and C. Cooper (eds.) Tourism in the age of globalization. London, England: Routledge, pp. 69-96.

4. Carbonell, P., Rodríguez-Escudero, A., and Pujari, D. (2012). 'Performance effects of involving lead users and close customers in new service development'. Journal of Services Marketing, 26(7), pp. 497-509.

5. Chesbrough, H. (2006). Open Business Models: How to Thrive in the New Innovation Landscape. Massachusetts, Boston: Harvard Business School Press. 
6. Chesbrough, H., \& Bogers, M. (2017). 'Explicating open innovation: clarifying an emerging paradigm for understanding innovation', in H. Chesbrough, W. Vanhaverbeke \& J. West (eds.), New Frontiers in Open Innovation. UK, Oxford: Oxford University Press, pp. 3-28.

7. Jong, J., Bruins, A., Dolfsma, W., \& Meijgaard J. (2003). Innovation in service firms explored: what, how and why? Strategic study B200205. Zoetermeer, Holland: EIM Business \& Policy Research. [Online] Available from: https://wilfreddolfsma.net/site/assets/files/1067/inn_in_ services_eim_final.pdf [Accessed 11/09/2019].

8. Djellal, F., and Gallouj, F. (2010). 'Services, innovation and performance: general presentation'. Journal of Innovation Economics \& Management, (1), pp. 5-15. [Online] Available from: https://halshs.archives-ouvertes.fr/halshs-01133785/document [Accessed 11/09/2019].

9. Egger, R., Gula, I., \& Walcher, D. (2016). 'Towards a Holistic Framework of Open Tourism', in Egger, R., Gula, I., Walcher, D. (eds.) Open Tourism: Open Innovation, Crowdsourcing and Co-Creation Challenging the Tourism Industry. Springer-Verlag Berlin Heidelberg, pp. 3-16.

10. Enkel, E., Gassmann, O., and Chesbrough, H. (2009). 'Open R\&D and Open Innovation: Exploring the Phenomenon'. R\&D Management, 39(4), pp. 311-316.

11. Evangelista, R. (2000). 'Sectoral patterns of technological change in services'. Economics of Innovation and New Technology, 9, pp. 182-221.

12. Gassmann, O., Enkel, E., and Chesbrough, H. (2004). 'Towards a theory of open innovation: three core process archetypes'. $R \& D$ Management Conference, Lisbon, Portugal, July 6-9.

13. Grassman, O., Enkel, L., and Chesbrough, H. (2010). 'Future of open innovation'. $R \& D$ Management, 40(3), pp. 213-221.

14. Hall, C.M., \& Williams, A. (2008). Tourism and Innovation. England, London: Routledge.

15. Hjalager, A.M. (2002). 'Repairing innovation defectiveness in tourism'. Tourism Management, 23(5), pp. 465-474.

16. Hjalager, A.M. (2010). 'A review of innovation research in tourism'. Tourism Management, 31(1), pp. 1-12.

17. Hogan, S., Soutar, G.N., McColl-Kennedy, J.R., and Sweeney, J.C. (2011). 'Reconceptualizing professional service firm innovation capability: Scale development'. Industrial Marketing Management, 40(8), pp. 1264-1273.

18. Love, J.H., Roper, S., and Bryson, J.R. (2011). 'Openness, knowledge, innovation and growth in UK business services.' Research Policy 40, pp. 1438-1452.

19. Mina, A., Bascavusoglu-Moreau, E., and Hughes, A. (2014). 'Open service innovation and the firm's search for external knowledge'. Research Policy, 43(5), pp. 853-866.

20. Orfila-Sintes, F., Crespí-Cladera, R., and Martínez-Ros, E. (2005). 'Innovation activity in the hotel industry: Evidence from Balearic Islands'. Tourism Management, 26(6), pp. 851-865.

21. Paget, E., Dimanche, F., and Mounet, J.P. (2010). 'A tourism innovation case: An ActorNetwork Approach'. Annals of Tourism Research, 37(3), pp. 828-847. [Online] Available from: http://isiarticles.com/ bundles/Article/pre/pdf/18611.pdf [Accessed 25/08/2019].

22. Pikkemaat, B., \& Peters, M. (2016). 'Open Innovation: A Chance for the Innovation Management of Tourism Destinations?' in Egger, R., Gula, I., Walcher, D. (eds.) Open Tourism: Open Innovation, Crowdsourcing and Co-Creation Challenging the Tourism Industry. Springer-Verlag Berlin Heidelberg, pp. 153-169.

23. Stamboulis, Y., and Skayannis, P. (2003). 'Innovation strategies and technology for experience-based tourism'. Tourism Management, 24(1), pp. 35-43.

24. Sundbo, J., Orfila-Sintes, F., and Sørensen, F. (2007). 'The innovative behaviour of tourism firms- Comparative studies of Denmark and Spain'. Research Policy, 36, pp. 88-106. 